\title{
A EDUCAÇÃO POPULAR COMO PRINCÍPIO DOS CURSINHOS POPULARES
}

\author{
Márcio F. de Carvalho ${ }^{1}$
}

\begin{abstract}
RESUMO: O presente texto tem como proposta falar sobre a busca dos Cursinhos Populares por uma formação diferenciada e tendo, para tanto, como princípio norteador, a Educação Popular, que tem como principal objetivo despertar nos envolvidos um espírito de cidadania e participação social, estimulando e promovendo, de forma dialógica e participativa, a formação de alunos críticos em relação ao mundo em que vivem. Outro ponto que também será abordado é a importância da articulação dos Cursinhos Populares enquanto Movimento Social.
\end{abstract}

Palavras-chave: Cursinhos Populares; Educação Popular; Movimento Social.

ABSTRACT: This text has the purpose to talk about the pursuit of Popular Preparatory Courses for a different training and have, therefore, as a guiding principle the Popular Education, which main goal involved in awakening a spirit of citizenship and social participation, encouraging and promoting, a dialogic and participatory way, in training critical students about the world in which they live. Another point that will also be addressed is the importance of coordination of a Popular Preparatory Course as Social Movement.

Keywords: Popular School; Popular Education; Social Movement.

\section{INTRODUÇÃO}

Em meio à grande desigualdade social brasileira e a má qualidade do ensino público, surgem os cursinhos pré-vestibulares como forma de preparação dos estudantes para superarem as dificuldades de acesso ao ensino superior. Estes cursinhos, no entanto, se tornaram máquinas de fazer dinheiro com mensalidades altíssimas, e, portanto, atingindo um público específico da sociedade.

É no sentido de inserir os estudantes que, por falta de condições materiais, não podem frequentar um pré-vestibular comercial, que surge em meados da década de setenta os Cursinhos Populares ou Comunitários, a partir de iniciativas do Movimento Estudantil e do Movimento Negro, visando que educandos/as oriundos de famílias das camadas populares pudessem ter melhores condições de ingressar no Ensino Superior, assim como

\footnotetext{
1 Graduação em História pela Universidade Federal de Viçosa (UFV). Integrante do Grupo de Estudos e Pesquisas Interdisciplinares em Sala de Aula (GEPISA).
} 
proporcionar autonomia, participação política e cidadã.

Sendo assim, os Cursinhos buscam uma educação que proporcione à classe trabalhadora um saber que seja instrumento de luta, para que estes estudantes se reconheçam como sujeitos históricos, ativos, reflexivos e capazes de transformar sua realidade. Desse modo, articulam-se com as comunidades rurais e urbanas, escolas e associações das cidades, buscando a construção de uma relação dialógica entre conhecimento científico e popular, enfatizando a valorização dos saberes populares e das culturas locais, regionais e valorizando a história de cada povo.

Os Cursinhos Populares tem atuado de modo a educar de forma sensível, crítica, ética e participativa, estimular a autonomia para transformação social, proporcionar um novo fazer pedagógico. Trata-se de um processo incansável que tem de estar em constante transformação e aprimoramento, devido às mudanças diárias que surgem em nossa sociedade.

Tomando por base todas estas características, uma educação diferenciada se faz mais do que necessária, e é neste sentido que os Cursinhos Populares buscam trabalhar com os princípios da educação popular, pois como mostra Brandão "a educação popular é uma ampla e difusa forma de trabalho político através da cultura e, mais diretamente, através de práticas pedagógicas abertas a vários campos sociais de educação e nunca restrita ao âmbito do sistema escolar". (BRANDÃO, 2002). Buscarei, portanto, compreender um pouco mais acerca dos Cursinhos populares em sua proposta educacional, filosófica e organizacional baseada nos princípios/pilares fundamentais da Educação Popular.

\section{A EDUCAÇÃO POPULAR COMO PRINCÍPIO NORTEADOR DAS PRÁTICAS PEDAGÓGICAS DOS CURSINHOS POPULARES}

A ideia de criar um Cursinho Popular vem da necessidade de se construir um espaço para que estudantes da camada popular possam se preparar para o processo seletivo de ingresso ao Ensino Superior, uma vez que as escolas públicas são ineficientes no que tange a essa preparação. Mas não se trata apenas do acesso as instituições de Ensino Superior. Os Cursinhos Populares tem como proposta político-pedagógica inserir as 
camadas populares nas Universidades tendo formada uma visão crítica em relação às mesmas da sociedade em que se encontram.

A Educação Popular tem como objetivo estimular, nos envolvidos, um espírito de cidadania e participação social promovendo de forma dialógica e participativa a formação de alunos críticos procurando respeitar cada conhecimento que o estudante traz para o âmbito escolar, pois todos os educandos são sujeitos sociais e históricos e não uma espécie de tábua rasa onde será depositado todo o conhecimento do professor. Trata-se de uma educação humanizadora, onde o professor é o norteador do processo sócioeducativo e não o detentor de todo o saber.

Para Freire (1987), a educação não é neutra, pois ao longo da história, ela tem sido usada como instrumento para manter a sociedade, principalmente a classe popular, alienada de seus direitos, manipulada pela classe dominante através de uma educação "bancária", na qual os estudantes são apenas depósitos de conhecimentos dos professores. Sendo assim, os estudantes não conseguem associar aquilo que aprendem a sua realidade, por isso consideram o ensino escolar chato e cansativo.

Ainda de acordo com Paulo Freire (1996), somos sujeitos inacabados, é isso que nos instiga a estar sempre à procura de novos conhecimentos. $O$ educador deve, portanto, ensinar e não transferir conhecimento, indicando diferentes caminhos para que o educando construa a sua autonomia.

Tanto educadores quanto educandos têm de estar em constante aprimoramento, pois, a educação popular não é um método padronizado, é um processo construído internamente nas comunidades, nos grupos, nas organizações populares, e no caso apresentado neste texto, nos Cursinhos Populares. Buscam-se assim formas de consolidação, ampliação e propagação dos direitos na luta por uma sociedade mais justa e igualitária.

A educação como instrumento de cidadania é, desse modo, utilizada pelos cursinhos em resistência à educação imposta por cursinhos comerciais. Assim podemos entender que:

Há duas concepções, portanto, de educação, entre as quais nós temos que optar: uma que está ligada a essa mercantilização, às "indústrias do conhecimento", que consideram qualidade como competitividade e pura dimensão econômica; e a outra que é a óptica da transformação, isto é, da educação como direito da condição humana, que forma o 
cidadão no espaço público, no espaço democrático, que leva em conta todas as dimensões do ser humano e que educa para a comunidade, para a humanidade (GADOTTI, 2002).

Desta forma, a educação popular torna-se fundamental para nortear o trabalho político-pedagógico e organizacional dos cursinhos. Cabe aos integrantes dos mesmos estarem sempre retomando a discussão através de espaços de formação, que tratem da importância deste princípio enquanto alicerce para o caráter político-pedagógico dos cursinhos populares.

Não obstante, este processo é incansável e tem que estar em constante transformação e aprimoramento devido às mudanças diárias que surgem em nossa sociedade. Para isso, os cursinhos [...] procuram fazer frente ao processo preparatório ao vestibular, revisando os conteúdos pertinentes para um bom desempenho de seus alunos. Porém, junto com essa tarefa que é intrínseca a um pré-vestibular, os cursinhos populares procuram se constituir como espaços de capacitação crítica das classes populares. (PEREIRA, 2007).

Neste sentido, novos métodos de ensino se fazem necessários na prática dos cursinhos, uma vez que procuram em sua proposta um novo fazer pedagógico, no qual a educação proporcione à classe trabalhadora um saber que seja instrumento de luta, de transformação social e que busque problematizar no espaço escolar o lado social do indivíduo, reconhecendo sua realidade histórica e exercendo sua cidadania.

Para Paulo Freire (1996) a educação verdadeira visa à humanização, a construção de uma vida social mais digna, livre e justa, baseando-se na realidade do educando, na construção de uma postura dialógica e dialética, não reduzida ao simples conhecer de letras, palavras e frases vazias.

Em seu texto, Santos (2006) fala de uma pedagogia "emancipatória" que busca a formação identitária dos sujeitos para que possam intervir na sociedade de modo ativo. $O$ autor aponta que esta é uma educação conflitante com o modelo de ensino dominante, pois, objetiva potencializar a indignação e a rebeldia, ou seja, é uma educação para o inconformismo, que busca formas para o desenvolvimento da democracia e para organização de relações sociais mais igualitárias, mais justas, edificantes e multiculturais, respeitando-se os "saberes" formais e cotidianos, valores e crenças dos indivíduos. 
É por buscar uma educação para a cidadania, visando a formação política e a transformação social, que acreditamos na educação popular como um princípio, pois:

A educação popular é uma educação comprometida e participativa orientada pela perspectiva de realização de todos os direitos do povo. Basea-se no saber da comunidade e incentiva o diálogo, visando a formação de sujeitos com conhecimento e consciência cidadã [...] A educação popular se dá a em um projeto destinado a formar pessoas para operarem transformações. (BRANDÃO, 2002).

Os Cursinhos Populares, portanto, espelham-se na Educação Popular, por se tratar não de um método padronizado, mas sim de um processo que se constrói internamente nos grupos e nas organizações populares, baseando-se na realidade das comunidades, dando visibilidade as mesmas.

Neste sentido é que os Cursinhos Populares optam pela educação que pensa a transformação da sociedade e não se rende às competitividades que em geral dominam os cursinhos comerciais. Penildon Filho afirma que os cursos pré-vestibulares populares fazem críticas aos cursos pré-vestibulares comerciais, e criam sua identidade principalmente a partir da negação do padrão comercial dos cursos no mercado (FILHO, 2004).

Os Cursinhos Populares buscam em sua prática cotidiana extrapolar 0 âmbito do ensino preparatório para o vestibular, buscam uma pedagogia libertadora, que dê visibilidade a classe popular, como sujeitos históricos, politicamente ativos no processo de transformação social, buscando renovar o ensino num processo de luta pela democratização da educação e direitos de todos, na busca pela universalização do acesso ao Ensino Superior, visto que, as formas de acesso ainda são excludentes e elitistas.

Acredita-se que para superar ou mesmo enfrentar tais desafios se faz necessária a organização e fortalecimento destes cursinhos. Por compartilhar experiências e se consolidarem num movimento em âmbito nacional.

\section{CURSINHOS POPULARES ENQUANTO MOVIMENTO SOCIAL: POR QUE NOS ARTICULA(R)MOS?}

Uma prática comum entre os Cursinhos Populares tem sido os encontros destes, que tem como objetivo a troca de experiências e o debate sobre 0 
acesso ao Ensino Superior, possibilitando assim uma articulação entre os mesmos. Tais encontros têm contribuído para um entendimento dos Cursinhos Populares enquanto um Movimento Social. Antes de tudo vale lembrar que os movimentos sociais

[...] são ações coletivas de caráter sociopolítico, construídas por atores sociais pertencentes a diferentes classes e camadas sociais. Eles politizam suas demandas e criam um campo político de força social na sociedade civil. (GOHN, 1995).

Os Movimentos Sociais no Brasil das décadas de 70 e 80, em pleno período de ditadura militar, foram demarcados com o surgimento de inúmeras formas de movimentos e formas organizativas populares, que reivindicavam direitos sociais tradicionais para sobrevivência do ser humano assim como a igualdade e a liberdade e a construção de uma democracia.

A prática de encontros entre os Cursinhos Populares tem reunido diversas organizações que lutam pela inclusão de um enorme contingente de pessoas oriundas das camadas populares nas Instituições Públicas de Ensino Superior. Nestes espaços encontram-se diversas oportunidades de discussão, como por exemplo, acerca da inserção dos educandos/as no Ensino Superior e o papel destes em suas comunidades, bem como no processo de decisão de suas localidades, abrangendo desta forma a capacidade de formulação crítica, tanto para o ENEM, vestibulares e outros exames de seleção, como para outros setores da vida, buscando, também, proporcionar um amadurecimento político-pedagógico dos educandos e educadores dos Cursinhos participantes.

Em relação aos últimos 10 anos, podemos citar: Fórum de Cursinhos Populares de Ribeirão Preto e região, Encontro de Cursinhos Populares, realizado na cidade de Campinas (2011), o Encontro de Cursinhos Populares em Viçosa (2012).

Podemos dizer que tais oportunidades de debate levam os cursinhos à discutirem suas bandeiras de luta e à fomentarem sua consolidação enquanto um Movimento Social para lutar pela democratização do acesso ao Ensino Superior e pela transformação da sociedade, buscando debater temas relevantes para os cursinhos e construir uma identidade coletiva entre os mesmos. 
Sobre criar uma identidade coletiva para a consolidação de um movimento, Gohn propõe:

\begin{abstract}
As ações sociopolíticas construídas por atores sociais coletivos se estruturam a partir de repertórios criados sobre temas e problemas em conflitos, litígios e disputas vivenciados pelo grupo na sociedade. As ações desenvolvem um processo social e político-cultural que cria uma identidade coletiva para o movimento, a partir dos interesses em comum. Esta identidade é amalgamada pela força do princípio da solidariedade e construída a partir da base referencial de valores culturais e políticos compartilhados pelo grupo, em espaços coletivos não institucionalizados (GOHN, 1995).
\end{abstract}

Nestes Encontros tem se buscado estratégias pedagógicas diferenciadas e troca de experiências entre todos os integrantes dos Cursinhos Populares presentes. Além disso, tem contribuído para a construção de parcerias com movimentos e organizações populares na luta por uma educação pública, gratuita e de qualidade. Além de temas como organização e bandeiras dos cursinhos populares, discutem-se os rumos da educação brasileira.

$\mathrm{Na}$ qualidade de movimento territorial, o Movimento dos Cursinhos, por meio de suas expressões mais significativas, trata-se de um espaço que delibera os rumos das políticas desenvolvidas para o conjunto da sociedade brasileira "[...]. a disputa desse espaço social faz dos Cursinhos Alternativos e Populares movimentos territoriais" (CASTRO, 2005).

A luta constante proporcionada pela Educafro, ACP-ZM, MSU, EDUCAFRO, rede Emancipa e pelos diversos Cursinhos de Universidades, Prefeituras, Sindicatos e comunidades em geral tem contribuído para recolocar em pauta na agenda do Estado brasileiro a educação e o acesso aos níveis superiores de ensino para as classes historicamente desprivilegiadas.

Os debates realizados nos encontros são de extrema importância para as mudanças pedagógicas e culturais destes cursinhos. As rodas de conversas, por exemplo, discutem a falta de materiais didáticos próprios para cursinhos populares como um dos grandes desafios dos educadores, visto que trabalham uma educação problematizadora, a educação vigente, e grande parte dos livros didáticos são publicados de modo a contemplar uma educação não crítica. 
Outro ponto recorrente nas reflexões de tais encontros é o porquê dá enorme evasão nos cursinhos populares ao longo do ano e neste sentido cabe sempre ressaltar a necessidade de um trabalho mútuo de recepção e integração, sejam estes agentes: coordenadores, educadores ou mesmos educandos. É neste sentido, que os encontros são fundamentais, pois a troca de saberes e de temas comuns entre os integrantes dos cursinhos é de suma importância para o posicionamento do mesmo perante a sociedade.

Apesar dos muitos desafios em mobilizar os integrantes dos cursinhos, é imprescindível que esta articulação aconteça e que as bandeiras de luta ganhem força no âmbito regional. Mais para além, que extrapole as fronteiras dos estados e consolide-se em um movimento social em todo o Brasil.

\section{CONSIDERAÇÕES FINAIS}

Buscou-se apresentar neste texto a busca pelo princípio da Educação Popular como orientador das práticas políticos pedagógicas dos Cursinhos Populares. Acreditando que os cursinhos populares almejam uma educação diferenciada, nada mais propício do que o entendimento e a apropriação da Educação Popular em seu cotidiano.

Como toda ação pedagógica é também uma ação política, faz-se necessário o fortalecimento da educação popular no aspecto pedagógico e em várias ações coletivas em prol de uma educação de qualidade e realmente para todos; um movimento social para democratização do acesso ao Ensino Superior e para a transformação da sociedade, buscando debater temas relevantes.

Numa perspectiva de emancipação e percebendo os desafios é que os cursinhos populares buscam a formação crítica do cidadão, em um processo de conscientização e luta pela universalização da educação, valorização do saber popular e de troca entre os saberes populares e os saberes científicos na busca da autonomia do sujeito.

É neste sentido que integrantes de tais cursinhos têm procurado se aproximar no dia-dia a fim de fortalecerem e somarem forças para avançar na luta por uma educação pública e de qualidade. 
Portanto, cabe-nos aqui reforçar a questão do "por que nos articula(r)mos?" Se observarmos que os cursinhos populares enfrentam desafios comuns como também almejam e apresentam perspectivas próximas, podemos compreender que é fundamental a organização e a troca de experiência entre estes.

Os cursinhos populares estão inseridos em tal processo como um movimento social popular que analisa as formas de lutas sociais organizadas no Brasil, buscando formas de consolidação, ampliação e propagação dos direitos, na luta por uma sociedade mais justa e igualitária. Acredita-se na importância destes encontros entre os cursinhos no processo de se tornarem um Movimento Social.

\section{REFERÊNCIAS BIBLIOGRÁFICAS}

BRANDÃO, Carlos Rodrigues. Soletrar a letra P: Povo, Popular, Partido e Política - E educação de vocação popular e o poder de Estado. In: FÁVERO, Osmar; SEMERARO, Giovani (orgs). A democracia e a construção do público no pensamento educacional brasileiro. 2. Ed. Petrópolis, RJ: Vozes, 2002.

CARVALHO, Márcio F. de; FREITAS, Maria Célia de. Perspectivas e desafios dos cursinhos populares da Zona da Mata Mineira. Revista ELO - Diálogos em Extensão, Viçosa, v. 2, n. 1, jul. 2013.

CASTRO, C. A. Cursinhos alternativos e populares: movimentos territoriais de luta pelo acesso ao ensino público superior no Brasil. 2005. Dissertação (Mestrado em Geografia) - Faculdade de Ciências e Tecnologia, Universidade Estadual Paulista "Júlio de Mesquita Filho", Presidente Prudente, 2005.

FÁVERO, Maria de Lourdes de Albuquerque. A Universidade do Brasil: um itinerário marcado por lutas. Revista Brasileira de Educação, Rio de Janeiro, n. 10, 1999.

FILHO, Penildon Silva. Cursos Pré-Vestibulares Populares em Salvador: Experiências Educativas em Movimentos Sociais. Revista Faced, Salvador, n. 8, 2004.

FREIRE, Paulo. Pedagogia da autonomia: saberes necessários à prática educativa. São Paulo: Paz e Terra, 1996.

Pedagogia do Oprimido. 17. Ed. Rio de Janeiro: Paz e Terra, 1987. 
1967.

. Educação como Prática da Liberdade. Ed. Rio de janeiro: Paz e Terra,

GOHN, Maria da Glória. História dos movimentos e lutas sociais: a construção da cidadania dos brasileiros. São Paulo: Loyola, 1995.

PEREIRA, Thiago Ingrassia. Pré-vestibulares populares em Porto Alegre: na fronteira entre o público e o privado. Dissertação de mestrado. UFRGS, Porto Alegre, 2007.

SANTOS, R. E. Pré-vestibulares Populares: Dilemas políticos e desafios pedagógicos. In: CARVALHO, José Carmelo et al. Cursos Pré-Vestibulares Comunitários: espaços de mediações pedagógicas. Rio de Janeiro: Ed. PUCRio, 2005.

SANTOS, Boaventura Sousa. Um Discurso Sobre as Ciências. 15. Ed. Porto: Edições Afrontamento, 2006.

SIQUEIRA, Camila Zucon Ramos de. Cursinhos Populares em movimento: articular e (re)conhecer contradições. Monografia (Graduação em Geografia) Universidade Federal de Viçosa, Viçosa, 2008.

Os cursinhos populares: um estudo comparado entre MSU e EDUCAFRO-MG. Dissertação (Mestrado em Educação) - Universidade Federal de Viçosa, Viçosa, 2011. 